\title{
Communication
}

\section{Increased PACAP- and D $\beta$ H-Positive Hepatic Nerve Fibers after Bisphenol A Exposure}

\author{
Michael Thoene ${ }^{1, * \mathbb{C}}$, Liliana Rytel ${ }^{2}$, Ewa Dzika ${ }^{1}$ and Joanna Wojtkiewicz ${ }^{3}$ (D) \\ 1 Department of Medical Biology, Faculty of Health Sciences, University of Warmia and Mazury in Olsztyn, \\ Żołnierska 14C Str., 10-561 Olsztyn, Poland; e.dzika@uwm.edu.pl \\ 2 Department of Internal Medicine and Clinic, Faculty of Veterinary Medicine, University of Warmia and \\ Mazury, Oczapowskiego Str 15, 10-718 Olsztyn, Poland; Liliana.Rytel@uwm.edu.pl \\ 3 Department of Pathophysiology, Faculty of Medical Sciences, University of Warmia and Mazury, \\ 10-718 Olsztyn, Poland; Joanna.Wojtkiewicz@uwm.edu.pl \\ * Correspondence: michael.thoene@uwm.edu.pl; Tel.: +48-89-524-61-16
}

Citation: Thoene, M.; Rytel, L.; Dzika, E.; Wojtkiewicz, J. Increased PACAP- and D $\beta$ H-Positive Hepatic Nerve Fibers after Bisphenol A Exposure. Toxics 2021, 9, 110. https://doi.org/10.3390/toxics9050110

Academic Editor: Pauline M. Anton

Received: 5 April 2021

Accepted: 15 May 2021

Published: 18 May 2021

Publisher's Note: MDPI stays neutral with regard to jurisdictional claims in published maps and institutional affiliations.

Copyright: (c) 2021 by the authors. Licensee MDPI, Basel, Switzerland. This article is an open access article distributed under the terms and conditions of the Creative Commons Attribution (CC BY) license (https:/ / creativecommons.org/licenses/by/ $4.0 /)$.

\begin{abstract}
Bisphenol A (BPA) is an endocrine-disrupting compound (EDC) that can be found nearly everywhere in our polluted world. BPA has been correlated with pathophysiologies that include psychological disorders, especially in children. This study used juvenile porcine models to investigate the effects of BPA on the liver of developing vertebrates in order to determine the effects of BPA on innervated hepatic samples with the use of double-labeled immunofluorescence. This study specifically investigated the sympathetic nervous system (SNS) colocalized with a specific neural marker (PACAP) that has previously been correlated with specific pathophysiologies in the literature. In the liver, it was observed that there were significantly increased nerve fibers in the SNS colocalized with the neural marker PACAP after exposure to BPA at concentrations considered to be "safe" with the same or more profound effects at higher exposure levels. The implications of childhood exposure to BPA are then discussed with regard to several correlation studies that have linked BPA exposure to behavioral/psychological disorders. It is possible that BPA exposure in childhood may upregulate the SNS and PACAP levels, thereby contributing to the correlations in the literature.
\end{abstract}

Keywords: bisphenol A; behavioral/psychological disorders; immunofluorescence technique; sympathetic nervous system; childhood exposure to BPA

\section{Introduction}

Bisphenol A (BPA) is a very common plastic polymer that has many uses, especially in the food industry. It has been used for decades as an epoxy resin to line canned foods and drinks, it is used in food packaging and food storage containers, and in some cities, it has even been used to line pipes that carry drinking water to households. Therefore, BPA has a very high toxic profile [1-3]. Products containing BPA and other bisphenols were originally considered to be safe, but recently it has been found that these bisphenol compounds act very much like estrogen in the body, and very small amounts can cause endocrine disruption. As an EDC (endocrine-disrupting compound), it is suspected of disrupting several endocrine system signaling pathways, including androgen receptors and thyroid hormone receptors even at nanogram concentrations [3]. This effect may be especially evident in developing vertebrates. The aim of this paper was to investigate the effects of BPA on innervated hepatic tissue taken from young porcine animal models at 8 weeks of age. Since much of the correlation literature points to the effects of bisphenol on developing human children, developing pigs were used in this study to simulate what may be happening in human children. This particular study used a marker for the sympathetic nervous system $(\mathrm{D} \beta \mathrm{H})$ colocalized with the neuronal marker PACAP in an effort to observe increased or decreased positive nerve fibers in the developing liver at low and high levels of BPA exposure, as compared to controls. In this communication, PACAP has the exclusive 
focus since our previously published work has already reported on several of the other neural markers within the sympathetic nervous system [4].

All of the involuntary systems of the body are controlled by the autonomic nervous system (ANS). It is split into two subtypes: the parasympathetic nervous system (PNS) and the sympathetic nervous system (SNS). The PNS controls the "rest and digest" functions of metabolism, while the SNS controls the "fight or flight" response. The SNS tends to have short neuronal pathways and very fast transduction times, which makes sense for a system designed to control a threat response. Mainly, the SNS controls levels of catecholamines, such as epinephrine, norepinephrine, and dopamine [5]. This study investigated the SNS of porcine liver for $\mathrm{D} \beta \mathrm{H}$ and PACAP in pigs at the age of 8 weeks. These neuronal markers have previously been described as "gut-brain" peptides [6]. Since most nutrients are absorbed in the small intestine and are quickly sent to the liver via the hepatic portal vein, this is relevant. Therefore, if dietary BPA increases or decreases the number of D $\beta \mathrm{H}$ or PACAP-positive nerve fibers, then the amount of BPA in the diet of the experimental models used in this study should quickly affect the innervation of the developing juvenile liver, as compared to control groups.

Any statistically significant changes in the number of $\mathrm{D} \beta \mathrm{H}$ - or PACAP-positive nerve fibers may be compared to previous correlation studies in the literature. This study used immunofluorescence assay techniques to colocalize dopamine beta-hydroxylase $(\mathrm{D} \beta \mathrm{H})$, a marker specific for the SNS, and pituitary adenylate cyclase-activating polypeptide (PACAP). $\mathrm{D} \beta \mathrm{H}$ is a catecholamine synthesis enzyme responsible for the production of adrenaline, as well as other related compounds. Increased levels of PACAP have been correlated with psychological disorders. Therefore, if either or both of these markers show increases after BPA administration, it could possibly indicate that BPA compounds are adversely affecting innervation patterns in children that could have observable clinical effects.

\section{Materials and Methods}

The present study was conducted on 15 immature sows of the Large White Polish breed at the age of 8 weeks and about $18-20 \mathrm{~kg}$ body weight. The animals were kept in typical laboratory conditions that had been adapted for this animal species. The experiment was carried out in compliance with the instructions of the Local Ethical Committee for Experiments on Animals in Olsztyn (Poland) (decision number 28/2013).

The animals were divided randomly into three groups after a 3-day adaptive period: (1) control group-placebo (empty gelatin capsules for 28 days during feeding); (2) experimental group I (received BPA capsules at a dose acceptable under European legislation $-0.05 \mathrm{mg}(50 \mu \mathrm{g}) / \mathrm{kg}$ bw/day); (3) experimental group II (received BPA capsules at a dose 10 times higher than the acceptable level $-0.5 \mathrm{mg} / \mathrm{kg} \mathrm{bw} /$ day). All pigs were weighed every four days before the morning feeding. This was done to determine their body weight and properly calculate the BPA dosage.

After administering BPA for 28 days, the pigs were premedicated using Stressnil (Janssen, Belgium, $75 \mu \mathrm{L} / \mathrm{kg}$ of body weight, i.m.). After approximately $30 \mathrm{~min}$, the animals were euthanized with a sodium thiopental overdose (Thiopental, Sandoz, KundlRakúsko, Austria, i.v.) and transcardially perfused with $4 \%$ buffered paraformaldehyde. Tissue samples were collected from all animals. Liver tissue sections were fixed in the paraformaldehyde solution mentioned above, rinsed for three days in phosphate buffer, and stored at $4{ }^{\circ} \mathrm{C}$ in $18 \%$ sucrose. After a minimum of two weeks, the liver fragments were frozen at $-23{ }^{\circ} \mathrm{C}$. They were then sliced using a microtome (Microm, HM 525, Walldorf, Germany) into $10 \mu \mathrm{m}$-thick sections and were subjected to a routine doublelabel immunofluorescence technique. This technique has been previously described by Gonkowski $[7,8]$ and Wojtkiewicz [6,9]. The following is a brief description of the abovementioned method: $45 \mathrm{~min}$ of drying followed by incubation with a blocking solution that included $0.1 \%$ bovine serum albumin, $10 \%$ normal goat serum, $0.01 \% \mathrm{NaN}_{3}$, thimerosal and Triton X-100 in PBS for $1 \mathrm{~h}$; incubation overnight with a mixture of two antibodies produced in different species (both were primary) and raised against dopamine beta-hydroxylase 
$(\mathrm{D} \beta \mathrm{H})$ and PACAP; and one hour of incubation using species-specific antisera that had been FITC- or biotin-conjugated. This was visualized with a streptavidin-CY3 complex. Table 1 specifies which primary and secondary antibodies were used in the present study. Between each of the stages, the sections were rinsed with PBS $(3 \times 10 \mathrm{~min}, \mathrm{pH}$ 7.4).

Table 1. Detailed list of primary and secondary antibodies used in the study.

\begin{tabular}{|c|c|c|c|c|}
\hline \multicolumn{5}{|c|}{ Primary Antibodies } \\
\hline Antisera & Code & Host Species & Dilution & Supplier \\
\hline $\mathrm{D} \beta \mathrm{H}$ & MAB 308 & mouse & 1:1000 & $\begin{array}{l}\text { Chemicon International Inc., UK; www.chemicon.com, } \\
12 \text { June } 2019\end{array}$ \\
\hline PACAP & IHC 8922 & rabbit & $1: 20,000$ & Bachem AG; www.bachem.com, 12 June 2019 \\
\hline \multicolumn{5}{|c|}{ Secondary Antibodies } \\
\hline & Reagent & & Dilution & Supplier \\
\hline \multicolumn{3}{|c|}{ Donkey anti-mouse IgG $(\mathrm{H}+\mathrm{L})$ conjugated with FITC } & $1: 800$ & $\begin{array}{c}\text { 715-095-151; Jackson IR Lab, US; } \\
\text { www.jacksonimmuno.com, } 12 \text { June } 2019\end{array}$ \\
\hline \multicolumn{3}{|c|}{ Biotinylated goat anti-rabbit immunoglobulins } & 1:1000 & $\begin{array}{l}\text { E0432, DAKO Corporation, US, www.dakousa.com, } \\
\text { 12 June } 2019\end{array}$ \\
\hline \multicolumn{3}{|c|}{$\begin{array}{l}\text { Biotin-conjugated } \mathrm{F}(\mathrm{ab})^{\prime} \text { fragment of affinity purified } \\
\text { anti-rabbit IgG }(\mathrm{H}+\mathrm{L})\end{array}$} & 1:1000 & $\begin{array}{l}\text { 711-1622, BioTrend, Germany; www.biotrend.com, } \\
12 \text { June } 2019\end{array}$ \\
\hline \multicolumn{3}{|c|}{ CY3-conjugated Streptavidin } & 1:9000 & $\begin{array}{l}\text { 016-160-084, Jackson IR Lab, US; } \\
\text { www.jacksonimmuno.com, } 12 \text { June } 2019\end{array}$ \\
\hline
\end{tabular}

Standard controls were conducted for the specificity of "primary" antibodies during this study, including the preabsorption of each particular antiserum with its appropriate antigen. Moreover, "omission" and "replacement" tests were performed that completely eliminated the immunofluorescence signals.

Two methods of evaluating the colocalization of DBH with PACAP were used. The first method consisted of determining the number of nerve fibers found in the field of view during microscopic examination of the three animal groups. The second method consisted of determining what percentage of all DBH-LI nerve fibers were neurally immunoreactive with PACAP. To this end, DBH-positive nerve fibers in hepatic tissues were examined for immunoreactivity with regard to PACAP. DBH-positive nerve fibers were considered as representing $100 \%$ for all combinations. This method was performed to determine what percentage of DBH-positive nerve fibers were immunoreactive with PACAP. Two independent investigators evaluated the immune-positive nerve fibers by counting the nerves. An Olympus BX51 microscope equipped with epifluorescence and appropriate filter sets was used to visualize the double-labeled nerve fibers. The results that were recorded were pooled and tabulated as a mean \pm SEM. In order to prevent the double counting of the same neuronal cells, all of the examined sections in this study were located at least $100 \mu \mathrm{m}$ apart. Student's $t$-test was used for statistical analysis (Graphpad Prism v. 6.0; GraphPad Software Inc., San Diego, CA, USA). Statistical significance for all differences was set at $p \leq 0.05$.

\section{Results}

\subsection{Significantly Increased Density of SNS Nerve Fibers}

In the innervated hepatic cells, there was an increased number of $\mathrm{D} \beta \mathrm{H}+$ nerve fibers observed after both low and high doses of dietary BPA as compared to the control samples. Even at suggested safe levels, $\mathrm{D} \beta \mathrm{H}$ was elevated. Compared to the control group, the number of $\mathrm{D} \beta \mathrm{H}+$ nerve fibers was increased by $48.6 \%$. Furthermore, when animals were exposed to 10 times above the recommended safe level of BPA, the number of $\mathrm{D} \beta \mathrm{H}+$ nerve fibers was $63.7 \%$ higher than the control samples. These results were statistically significant. 
Since $\mathrm{D} \beta \mathrm{H}$ is generally accepted to be a marker for the SNS, these results suggest an upregulation of the SNS after either low or high BPA exposure.

\subsection{Significantly Increased Density of PACAP+/D $B H+$ Nerve Fibers Colocalized in the SNS}

Compared to the control group, the number of PACAP+/D $\beta \mathrm{H}+$ nerve fibers observed after exposure to suggested safe levels of BPA was increased by $166.7 \%$. Moreover, when animals were exposed to 10 times above the recommended safe level of BPA, the $\mathrm{PACAP}+/ \mathrm{D} \beta \mathrm{H}+$ nerve fiber count was $135.6 \%$ higher than the control. All results showed statistical significance. The above-mentioned results are presented in Table 2. Representative images of $\mathrm{D} \beta \mathrm{H} / \mathrm{PACAP}$ immunocytochemical colocalization are shown in Figure 1.

Table 2. Changes in the count of intrahepatic sympathetic nerve fibers as well as altered neurochemical characteristics after exposure to BPA under physiological conditions.

\begin{tabular}{cccc}
\hline \multirow{2}{*}{$\begin{array}{c}\text { Neurochemical } \\
\text { Characteristic }\end{array}$} & Groups of Animals \\
\cline { 2 - 4 } & CTRL & E1 & E2 \\
\hline D $\beta H+$ & $21.2 \pm 2.08$ & $31.5 \pm 1.85$ & $34.7 \pm 1.61$ \\
D $3 \mathrm{H}+/ \mathrm{PACAP}+$ & $9.0 \pm 2.07$ & $24.0 \pm 3.16$ & $21.2 \pm 3.81$ \\
\hline
\end{tabular}

Studied groups of animals: C-control; E1-experimental group 1 (low dose of bisphenol A); E2-experimental group 2 (high dose of bisphenol A). All results are statistically significant.
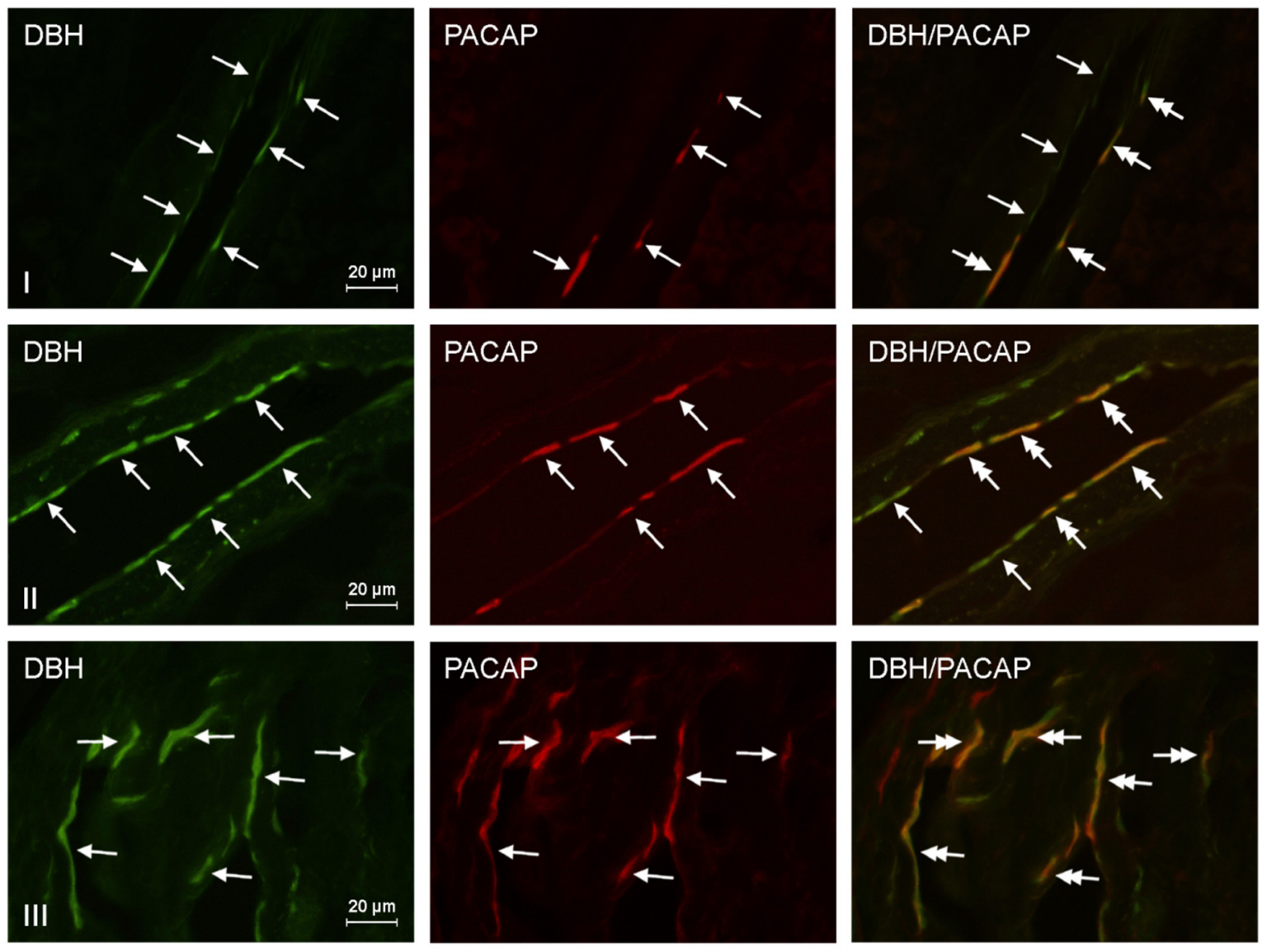

Figure 1. Representative images of the immunocytochemical localization of $\mathrm{D} \beta \mathrm{H}$ - and PACAP-immunoreactive nerve fibers in intrahepatic sympathetic nerves (arrows) of the control group (CTRL, (I)), experimental group 1 (E1, low dose of bisphenol A; (II)), and experimental group 2 (E2, high dose of bisphenol A, (III)). D $\beta \mathrm{H}$ or PACAP-IR nerve fibers are indicated with arrows; $\mathrm{D} \beta \mathrm{H}$ and PACAP-IR nerve fibers are indicated with double-headed arrows; scale bars in all figures represent $20 \mu \mathrm{m}$. 


\section{Discussion}

Dopamine beta-hydroxylase has been known as an enzyme important for proper neural functioning for over fifty years. Patients who are born without a functional gene encoding for $\mathrm{D} \beta \mathrm{H}$ have severe health problems characterized by increased dopamine levels and the complete absence of epinephrine and norepinephrine in the blood plasma [10]. $\mathrm{D} \beta \mathrm{H}$ is a membrane-bound copper-conjugated oxygenase that catalyzes the conversion of dopamine to norepinephrine. $\mathrm{D} \beta \mathrm{H}$ also uses ascorbate as a cofactor. The lack of this enzyme in humans is quite rare but allowed clinical scientists to characterize this protein quite early on. The lack of a functional $\mathrm{D} \beta \mathrm{H}$ enzyme will not allow the production of adrenaline from dopamine, which is essential for the sympathetic nervous system to function properly. $\mathrm{D} \beta \mathrm{H}$ is expressed in both the central nervous system and peripheral nervous system in noradrenergic nerve terminals. It is also expressed in chromaffin cells located inside of the adrenal medulla, which is responsible for catecholamine production [11,12]. Therefore, $\mathrm{D} \beta \mathrm{H}$ is crucial for the initiation of the sympathetic nervous system and the resulting "fight or flight" response. For this reason, $\mathrm{D} \beta \mathrm{H}$ is commonly used as a marker for the SNS, and this study used $\mathrm{D} \beta \mathrm{H}$ to investigate the hepatic nerve fibers of the sympathetic nervous system after exposure to varying levels of BPA.

$\mathrm{D} \beta \mathrm{H}$ has been visualized quite often via immunohistochemistry using human tissues and various animal models. For example, $\mathrm{D} \beta \mathrm{H}$ versus tyrosine hydroxylase was visualized using differential staining in the human hindbrain while investigating catecholamines [13]. In addition, the determination of expression of $\mathrm{D} \beta \mathrm{H}$ in the locus coeruleus of neonate rats after exposure to a commonly used herbicide was similar in methodology to the current study [14]. The studies just mentioned used immunostaining techniques that are similar to what was used in this study but were conducted on nervous tissue. The technique was expanded to include innervated tissues. More recently, this type of immunofluorescence has been used to investigate $\mathrm{D} \beta \mathrm{H}$ colocalized in innervated tissues with neural markers, including PACAP. Their goal was to observe changes in neural markers in the ovaries of women suffering from polycystic ovary syndrome [15]. Those same immunofluorescence techniques were used in this study of innervated hepatic tissue.

As can be seen with the D $\beta H$ concentrations in this study, even legally "safe" levels of BPA cause a statistically significant increase in $\mathrm{D} \beta \mathrm{H}$ expression. Since $\mathrm{D} \beta \mathrm{H}$ is mainly responsible for the synthesis of catecholamines, young vertebrates exposed to BPA will have increased levels of adrenaline in their liver and perhaps within their system even under normal nonstress conditions. This may lead to an increased fight or flight response, as well as problems with energy metabolism. Since the catecholamines epinephrine and norepinephrine increase heart rate and alertness, the elevated levels of $\mathrm{D} \beta \mathrm{H}$ could possibly contribute to an increase in aggressive behavior, stress disorders, and increased rates of ADHD that have been previously correlated with BPA exposure in children, as described by several research teams [16-19]. Furthermore, increased catecholamines tend to change the normal functioning of energy metabolism by primarily affecting digestion and glucose levels. Therefore, it is possible that the increased levels of hepatic $\mathrm{D} \beta \mathrm{H}$ may be behind the correlations of childhood obesity and diabetes that have been described by other research teams $[20,21]$. Although these are correlations found in children, they will most likely have life-long implications. ADHD and increased aggressive behavior will be a detriment to childhood education, for example, which may negatively impact the standard of living later in life. Increased BMI and diabetes usually affect individuals throughout their entire life and are known to reduce life expectancy in adulthood. However, future research would need to be performed in order to verify that these negative trends persist into later life. As a marker for the SNS, D $\beta H$ shows signs that catecholamines are elevated in innervated hepatic tissue after BPA exposure, even at levels that are currently considered to be safe in humans. However, this study also colocalized D $\beta \mathrm{H}$ with another neuronal "gut-brain" marker, PACAP. $\mathrm{D} \beta \mathrm{H}$ shows that the effects occur in the SNS, while the PACAP marker indicates a change in specific neurochemical coding. 
The marker that was colocalized with $\mathrm{D} \beta \mathrm{H}$ was PACAP. PACAP has been known to increase the amount of cAMP within cells, which is an important signaling molecule in many cellular pathways. PACAP has also been shown to increase the activity of the pituitary gland, and it acts in a similar way to vasoactive intestinal peptide (VIP), which is often expressed in the PNS [6,22]. Increased levels of PACAP have been associated with PTSD and other mental disorders in a well-known article published in the journal Nature [23]. Our results show that the level of $\mathrm{D} \beta \mathrm{H}$ colocalized with PACAP increases dramatically at recommended safe levels and then remains roughly at the same level even at higher bisphenol exposure levels. At suggested safe levels, colocalized PACAP+/D $\beta \mathrm{H}+$ is $166.7 \%$ higher when compared to controls, while at 10 times the safe exposure level, colocalized $\mathrm{PACAP}+/ \mathrm{D} \beta \mathrm{H}+$ is $135.6 \%$ higher than the control samples. It is safe to assume that BPA at recommended safe levels is already causing the maximum amount of PACAP+ nerve fibers, which is nearly three times higher when compared to the control samples. If these increases in colocalized nerve fibers are also occurring in the developing human population, the drastically increased PACAP+ $/ \mathrm{D} \beta \mathrm{H}+$ nerve fibers could be indicative of increased behavioral and psychological disorders in children and young adults, such as increased aggressive behavior, ADHD, and other psychological disorders. In order to confirm such a hypothesis, many more studies would need to be conducted; however, it appears to be more than just a possibility. The correlation between these psychological effects and BPA exposure has been described by numerous authors in various studies $[16,17,19,24]$. These studies have all positively correlated increased urine or plasma BPA levels with increased behavioral disorders in children and adolescents. Since dietary toxins come into contact with the liver before other organ systems, the effects may be more pronounced than in other innervated tissues. However, PACAP expression at nearly 3 times normal levels in the liver is indicative of increased expression throughout the entire neuronal system as well as in most other innervated tissues. Therefore, further studies are required to confirm or contradict that $\mathrm{PACAP}+/ \mathrm{D} \beta \mathrm{H}+$ nerve fibers are also elevated in other nervous systems of the developing vertebrate after BPA exposure.

It is very possible for a developing child to become exposed to at least 10 times the legal safe amount of BPA, since it is found everywhere in the polluted world and many parents may still be unaware of the dangers of BPA exposure, especially in developing countries [25]. Therefore, it is recommended to perhaps revise the current suggested safe levels of BPA exposure downward, as well as increase the awareness of the public to the potential dangers of BPA—especially with regard to children.

\section{Conclusions}

This study aimed to analyze the effects of a very common EDC (BPA) on the nerve fibers of the developing liver, as compared to a control group. The correlation effects seem to be mainly observed in human children, even though those effects may not be limited to children only. Therefore, this study observed nerve fibers in the SNS portion of the autonomic nervous system of the developing porcine liver after exposure to varying levels of BPA and compared the results to an identical control group with no BPA exposure.

The number of $\mathrm{D} \beta \mathrm{H}$ nerve fibers was significantly increased, which indicates an overly active SNS. This seems to be evidence that bisphenol exposure at recommended safe levels is still too high, especially for children. It is hoped that this study may be an early step in determining if BPA exposure is upregulating the SNS as well as PACAP nerve fibers which may lead to pathological disease states that have already been correlated with bisphenol exposure. More studies should be performed using these neuronal markers to test other innervated tissues as well as the central nervous system and peripheral nervous systems. Using innervated hepatic tissue to test ingested BPA exposure is logical, since the liver is the first major organ exposed to dietary toxins. By testing increased or decreased colocalization in the liver, we have shown that BPA is causing significant changes. Hopefully, in a relatively short time, we may have a more detailed picture of how BPA is affecting the various nervous systems during child development. 
Author Contributions: Data curation, L.R.; formal analysis, M.T.; funding acquisition, E.D.; investigation, L.R.; methodology, J.W.; project administration, J.W.; resources, E.D. and J.W.; supervision, J.W.; validation, writing—original draft, M.T.; writing—review and editing, M.T. All authors have read and agreed to the published version of the manuscript.

Funding: This research was funded by the University of Warmia and Mazury in Olsztyn (No. 61610001-100).

Institutional Review Board Statement: The experiment was carried out in compliance with the instructions of the Local Ethical Committee for Experiments on Animals in Olsztyn (Poland) (decision number 28/2013).

Informed Consent Statement: Not applicable.

Data Availability Statement: Data sharing not applicable.

Acknowledgments: This study was supported by the statutory grant No. 63-610-001, from the University of Warmia and Mazury in Olsztyn, Poland. No part of this article is under consideration, in whole or in part, by any other journal. No part of this article has been copied from any other source, unless it has been clearly cited within the work itself. No tables or figures have been copied from any previous work. I certify that my institution has approved the protocol for the investigation involving animals and that all experimentation was conducted in conformity with ethical and humane principles of research. All authors contributed in equal part to this work. I, as well as the co-authors, declare no conflict of interest.

Conflicts of Interest: The authors declare no conflict of interest.

$\begin{array}{ll}\text { Abbreviations } \\ \text { ANS } & \text { autonomic nervous system } \\ \text { BPA } & \text { bisphenol A } \\ \text { D } \beta H & \text { dopamine beta-hydroxylase } \\ \text { EDC } & \text { endocrine-disrupting compound } \\ \text { PACAP } & \text { pituitary adenylate cyclase-activating polypeptide } \\ \text { PSNS } & \text { parasympathetic nervous system } \\ \text { SNS } & \text { sympathetic nervous system } \\ \text { VIP } & \text { vasoactive intestinal peptide }\end{array}$

\section{References}

1. Beronius, A.; Ruden, C.; Hakansson, H.; Hanberg, A. Risk to all or none? A comparative analysis of controversies in the health risk assessment of Bisphenol A. Reprod. Toxicol. 2010, 29, 132-146. [CrossRef] [PubMed]

2. Reif, D.M.; Martin, M.T.; Tan, S.W.; Houck, K.A.; Judson, R.S.; Richard, A.M.; Knudsen, T.B.; Dix, D.J.; Kavlock, R.J. Endocrine profiling and prioritization of environmental chemicals using ToxCast data. Environ. Health Perspect. 2010, 118, 1714-1720. [CrossRef] [PubMed]

3. Vandenberg, L.N.; Ehrlich, S.; Belcher, S.M.; Ben-Jonathan, N.; Dolinoy, D.C.; Hugo, E.R.; Hunt, P.A.; Newbold, R.R.; Rubin, B.S.; Saili, K.S.; et al. Low dose effects of bisphenol A. Endocr. Disruptors 2013, 1, e26490. [CrossRef]

4. Thoene, M.; Godlewski, J.; Rytel, L.; Dzika, E.; Bejer-Oleńska, E.; Wojtkiewicz, J. Neurochemical Coding of Porcine Intrahepatic Sympathetic Nerves under Physiological Conditions and after Bisphenol A Administration. Folia Histochem. Cytobiol. 2018, 1, 113-121. [CrossRef] [PubMed]

5. Jensen, K.J.; Alpini, G.; Glaser, S. Hepatic Nervous System and Neurobiology of the Liver. Compr. Physiol. $2013,3,655-665$. [CrossRef] [PubMed]

6. Wojtkiewicz, J.; Makowska, K.; Bejer-Olenska, E.; Gonkowski, S. Zinc Transporter 3 (Znt 3 ) as an Active Substance in the Enteric Nervous System of the Porcine Esophagus. J. Mol. Neurosci. 2017, 61, 315-324. [CrossRef] [PubMed]

7. Gonkowski, S.; Kaminska, B.; Landowski, P.; Całka, J. Immunohistochemical distribution of cocaine- and amphetamine-regulated transcript peptide-like immunoreactive (CART-LI) nerve fibers and various degree of co-localization with other neuronal factors in the circular muscle layer of human descending colon. Histol. Histopathol. 2013, 28, 851-858. [CrossRef]

8. Gonkowski, S.; Rowniak, M.; Wojtkiewicz, J. Zinc transporter 3 (ZnT3) in the enteric nervous system of the porcine ileum in physiological conditions and during experimental inflammation. Int. J. Mol. Sci. 2017, 18, 338. [CrossRef]

9. Wojtkiewicz, J.; Rytel, L.; Makowska, K.; Gonkowski, S. Co-localization of zinc transporter $3\left(\mathrm{ZnT}_{3}\right)$ with sensory neuromediators and/or neuromodulators in the enteric nervous system of the porcine esophagus. Biometals 2017, 30, 393-403. [CrossRef]

10. Senard, J.M.; Rouet, P. Dopamine beta-hydroxylase deficiency. Orphanet J. Rare Dis. 2006, 1, 7. [CrossRef] 
11. Erez, A.; Li, J.; Geraghty, M.T.; Ben-Shachar, S.; Cooper, M.L.; Mensing, D.E.; Vonalt, K.D.; Ou, Z.; Pursley, A.N.; Chinault, A.C.; et al. Mosaic deletion 11p13 in a child with dopamine beta-hydroxylase deficiency-Case report and review of the literature. Am. J. Med. Genet. A 2010, 152, 732-736. [CrossRef] [PubMed]

12. Kim, C.H.; Leung, A.; Huh, Y.H.; Yang, E.; Kim, D.J.; Leblanc, P.; Ryu, H.; Kim, K.; Kim, D.W.; Garland, E.M.; et al. Norepinephrine Deficiency Is Caused by Combined Abnormal mRNA Processing and Defective Protein Trafficking of Dopamine $\beta$-Hydroxylase. J. Biol. Chem. 2011, 286, 9196-9204. [CrossRef] [PubMed]

13. Kitahama, K.; Sakamoto, N.; Jouvet, A.; Nagatsu, I.; Pearson, J. Dopamine-beta-hydroxylase and tyrosine hydroxylase immunoreactive neurons in the human brainstem. J. Chem. Neuroanat. 1996, 10, 137-146. [CrossRef]

14. García, G.B.; Konjuh, C.; Duffard, R.O.; Evangelista de Duffard, A.M. Dopamine-beta-hydroxylase immunohistochemical study in the locus coeruleus of neonate rats exposed to 2,4-dichlorophenoxyacetic acid through mother's milk. Drug Chem. Toxicol. 2006, 29, 435-442. [CrossRef] [PubMed]

15. Wojtkiewicz, J.; Jana, B.; Kozłowska, A.; Crayton, R.; Majewski, M.; Zalecki, M.; Baranowski, W.; Radziszewski, P. Innervation pattern of polycystic ovaries in the women. J. Chem. Neuroanat. 2014, 61-62, 147-152. [CrossRef]

16. Miodovnik, A.; Engel, S.M.; Zhu, C.; Ye, X.; Soorya, L.V.; Silva, M.J.; Calafat, A.M.; Wolff, M.S. Endocrine disruptors and childhood social impairment. Neurotoxicology 2011, 32, 261-267. [CrossRef]

17. Braun, J.M.; Yolton, K.; Dietrich, K.N.; Hornung, R.; Ye, X.; Calafat, A.M.; Lanphear, B.P. Prenatal bisphenol A exposure and early childhood behavior. Environ. Health Perspect. 2009, 117, 1945-1952. [CrossRef]

18. Braun, J.M.; Kalkbrenner, A.E.; Calafat, A.M.; Yolton, K.; Ye, X.; Dietrich, K.N.; Lanphear, B.P. Impact of early life bisphenol A exposure on behavior and executive function in children. Pediatrics 2011, 128, 873-882. [CrossRef]

19. Perera, F.; Vishnevetsky, J.; Herbstman, J.B.; Calafat, A.M.; Xiong, W.; Rauh, V.; Wang, S. Prenatal bisphenol a exposure and child behavior in an inner-city cohort. Environ. Health Perspect. 2012, 120, 1190-1194. [CrossRef]

20. Trasande, L.; Attina, T.M.; Blustein, J. Association between urinary bisphenol A concentration and obesity prevalence in children and adolescents. JAMA 2012, 308, 1113-1121. [CrossRef]

21. Wang, H.X.; Zhou, Y.; Tang, C.X.; Wu, J.G.; Chen, Y.; Jiang, Q.W. Association between bisphenol A exposure and body mass index in Chinese school children: A cross-sectional study. Environ. Health 2012, 11, 79. [CrossRef] [PubMed]

22. Thoene, M.; Rytel, L.; Dzika, E.; Włodarczyk, A.; Kruminis-Kaszkiel, E.; Ptaszyński, K.; Wojtkiewicz, J. Bisphenol A Causes Liver Damage and Selectively Alters the Neurochemical Coding of Intrahepatic Parasympathetic Nerves in Juvenile Porcine Models under Physiological Conditions. Int. J. Mol. Sci. 2017, 18, 2726. [CrossRef] [PubMed]

23. Ressler, K.J.; Mercer, K.B.; Bradley, B.; Jovanovic, T.; Mahan, A.; Kerley, K.; Norrholm, S.D.; Kilaru, V.; Smith, A.K.; Myers, A.J.; et al. Post-traumatic stress disorder is associated with PACAP and the PAC1 receptor. Nature 2011, 470, 492-497. [CrossRef] [PubMed]

24. Maserejian, N.N.; Trachtenberg, F.L.; Hauser, R.; McKinlay, S.; Shrader, P.; Bellinger, D.C. Dental composite restorations and neuropsychological development in children: Treatment level analysis from a randomized clinical trial. Neurotoxicology 2012, 33, 1291-1297. [CrossRef] [PubMed]

25. Thoene, M.; Rytel, L.; Nowicka, N.; Wojtkiewicz, J. The state of bisphenol research in the lesser developed countries of the EU: A mini-review. Toxicol. Res. 2018, 7, 371-380. [CrossRef] [PubMed] 